\title{
Hidatidosis en niños: experiencia en un hospital de alta complejidad fuera del área endémica
}

\author{
Echinococcosis in children: Experience in a tertiary care hospital outside the endemic area
}

\author{
Dra. Griselda Berberian ${ }^{a}$, Dra. M. Teresa Rosanova ${ }^{a}$, Dra. Laura Inda ${ }^{a}$, Dra. Claudia Sarkis ${ }^{a}$, \\ Dr. Horacio Questa ${ }^{b}$ Bioq. Patricia Paulin ${ }^{c}$, Bioq. Marina Costa ${ }^{d}$ y Dra. Moira Taicz ${ }^{a}$
}

\section{RESUMEN}

La hidatidosis es una zoonosis con una amplia distribución en Argentina y en el mundo. Se adquiere en la infancia, pero se presenta, más frecuentemente, en la edad adulta. La población pediátrica representa el 10\%-20\% del total de los casos. Se presentan 47 niños con diagnóstico de hidatidosis duranteun período de 20 años. La mediana de edad fue de 8 años (rango: 3-17)y, en su mayoría, tenían algún antecedenteepidemiológico orientador, como la procedencia de un área endémica, rural y/o la tenencia de perros alimentados con vísceras. El 85\% fueron quistes únicos localizados en un solo parénquima. Las localizaciones quísticas pulmonares y hepáticas fueron las más frecuentemente encontradas. El tratamiento fue médicoquirúrgico en 45 pacientes (96\%). Trece (28\%) presentaron alguna complicación posterior, que fue más frecuente en aquellos con localización pulmonar. Tres $(6 \%)$ recayeron entre el mes y los 24 meses, y requirieron una nueva cirugía. Ninguno falleció a causa de la enfermedad parasitaria.

Palabras clave: hidatidosis, niño.

http: / / dx.doi.org/10.5546/ aap.2017.282

Texto completo en inglés:

http:/ / dx.doi.org/10.5546/ aap.2017.eng.282

Cómo citar: Berberian G, Rosanova MT, Inda L, et al. Hidatidosis en niños: experiencia en un hospital de alta complejidad fuera del área endémica. Arch Argent Pediatr 2017;115(3):282-286.

a. Servicio de Epidemiología e Infectología del Hospital de Pediatría "Prof. Dr. Juan P. Garrahan", Ciudad Autónoma de Buenos Aires, Argentina.

b. Servicio de Cirugía del Hospital de Pediatría "Prof. Dr. Juan P. Garrahan", Ciudad Autónoma de Buenos Aires, Argentina.

c. Laboratorio: Sección Parasitología del Hospital de Pediatría "Prof. Dr. Juan P. Garrahan", Ciudad Autónoma de Buenos Aires, Argentina.

d. Laboratorio: Sección Serología del Hospital de Pediatría "Prof. Dr. Juan P. Garrahan", Ciudad Autónoma de Buenos Aires, Argentina.

Correspondencia:

Dra. Griselda Berberian, griselberberian@yahoo.com.ar

Financiamiento: Ninguno.

Conflicto de intereses: Ninguno que declarar.

Recibido: 21-7-2016

Aceptado: 5-12-2016

\section{INTRODUCCIÓN}

La hidatidosis es una parasitosis zoonótica causada por cestodos del género Echinococcus. El único que tiene relevancia clínica en el continente americano es el Echinococcus granulosus. La enfermedad es causada por su forma larvaria, de la que el hombre resulta ser un huésped accidental. Es la causa más frecuente de quistes hepáticos en el mundo y se encuentra dentro de las enfermedades más olvidadas. ${ }^{1}$ (Figura 1 ). Es endémica en Argentina, con más de 300 casos nuevos por año. ${ }^{2,3}$

\section{OBJETIVO}

Conocer la epidemiología, las características clínicas, el tratamiento y la evolución de los niños con hidatidosis internados en un hospital pediátrico de alta complejidad fuera de la zona endémica.

\section{POBLACIÓN Y MÉTODOS}

Revisión retrospectiva de las historias clínicas de niños $\leq 18$ años con infección por E. granulosus sobre la base de los criterios internacionales diagnósticos de la Organización Mundial de la Salud (OMS), que consideran la epidemiología, clínica, imágenes, anatomía patológica, serología y parasitología. ${ }^{4}$

El período de estudio fue de 20 años (mayo de 1993-octubre de 2013).

Las variables de interés que se buscaron fueron: edad, sexo, procedencia, factores de riesgo, diagnóstico clínico, imágenes, análisis de laboratorio general, serológico, tratamiento y evolución.

Se consideró epidemiología positiva a la presencia de uno o más factores de riesgo de adquisición, como procedencia de un área endémica, zona rural, tenencia de perros. La serología utilizada fue el enzimoinmunoanálisis de adsorción (enzyme-linked immunosorbent assay; ELISA, por sus siglas en inglés) confirmada por Western blot en situaciones especiales. Los estudios por imágenes se seleccionaron en función de la localización y la clínica de presentación. 
Los datos fueron procesados en la base EpiInfo 6.0. Las variables continuas, informadas como media o medianas y rango. Las variables categóricas se expresaron como número y porcentaje.

\section{RESULTADOS}

Se incluyeron 47 pacientes con una mediana de 8 años. Por tratarse de un hospital de derivación, la procedencia fue variada, con 43 pacientes $(91 \%)$ argentinos y 4 (9\%) de origen boliviano. Las zonas de procedencia de la Argentina correspondieron a la provincia de Buenos Aires (20 pacientes, $47 \%$ ), al Noreste (9 pacientes, $21 \%$ ), al Noroeste (7 pacientes, $16 \%$ ) y a la Patagonia (7 pacientes, $16 \%)$.

En cuarenta pacientes (85\%), los quistes estaban localizados en un solo parénquima. De las 54 localizaciones quísticas, la pulmonar y la hepática fueron las más frecuentes y 45 pacientes $(96 \%)$ recibieron tratamiento médico-quirúrgico. Trece pacientes $(28 \%)$ presentaron alguna complicación. Las complicaciones pulmonares fueron fístula broncopleural, neumotórax, paresia diafragmática, atelectasia y bacteriemia por Staphylococcus aureus. Las complicaciones para la localización cerebral fueron ruptura quística intraquirúrgica e hidrocefalia. De la localización hepática complicada, todos tuvieron problemas relacionados con infecciones, como absceso de pared y absceso hepático secundario. Tres pacientes $(6 \%)$ recayeron entre el mes y los 24 meses, y requirieron de una nueva cirugía (Tabla 1).

\section{DISCUSIÓN}

En las Américas, la mayor cantidad de hidatidosis están reportadas en el sur del continente. Existen distintas especies según el área geográfica con, al menos, 10 tipos genéticos diferentes de E. granulosus. ${ }^{5}$

En Argentina, se distribuye en todo el territorio nacional, especialmente, en las zonas rurales con cría de ganado ovino y caprino localizadas en la Patagonia, la Mesopotamia, la Pampa húmeda, Cuyo y el Noroeste. ${ }^{6}$

Debido a que la hidatidosis corresponde a una zoonosis, los antecedentes epidemiológicos son esenciales para la orientación diagnóstica. El espectro clínico va desde formas asintomáticas a formas graves, pero, raramente, fatales, dependiendo de la localización, el tamaño, las características del quiste y la presencia o no de complicaciones.

Compromete, en primer lugar, el hígado $(67 \%$ $89 \%) \mathrm{y}$, con menos frecuencia, los pulmones $(10 \%$ $25 \%)$. Puede presentarse en el bazo (1\%-3\%), el peritoneo $(3 \%-5 \%)$, los riñones $(2 \%)$, el cerebro $(2 \%)$ y, más raramente, el corazón, el hueso, el páncreas y la órbita. ${ }^{7-9}$ Las localizaciones atípicas

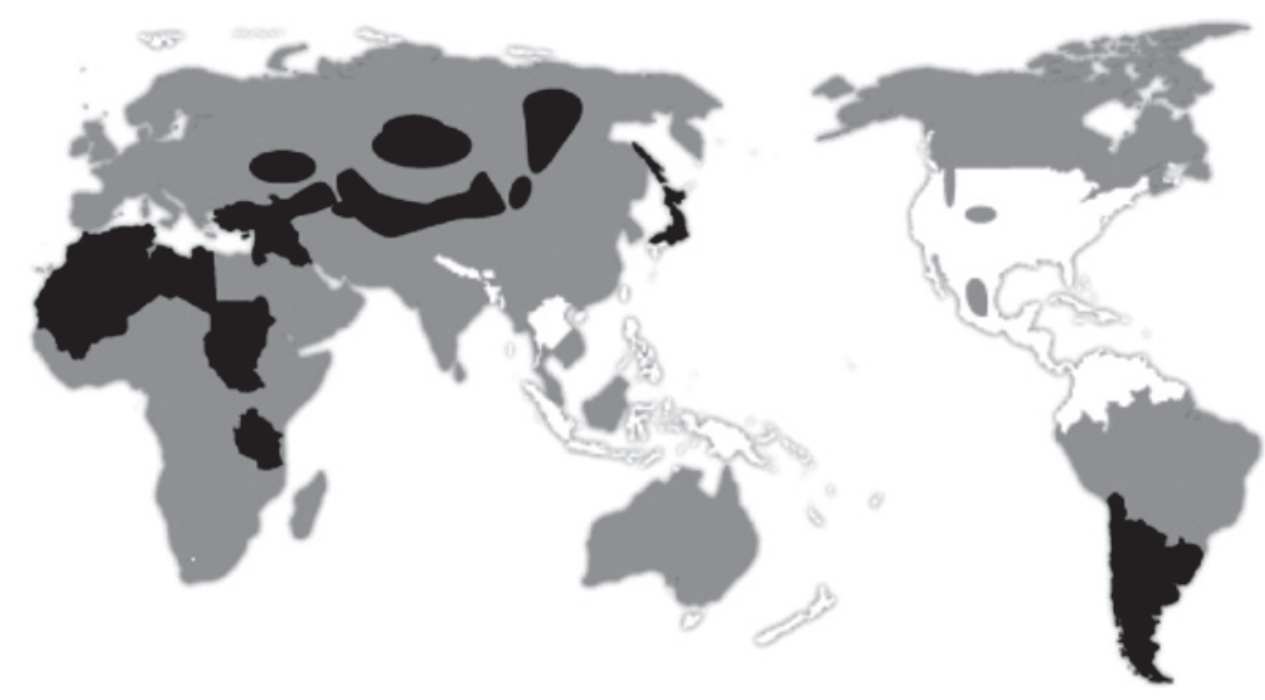

Zonas hiperendémicas de hidatitosis. 
y complicadas son las que requieren del manejo en hospitales de mayor complejidad.

Del $60 \%$ al $80 \%$ de los quistes son únicos. En la serie presentada, con más frecuencia, se halló la presencia de quistes únicos en un solo parénquima; el pulmón y el hígado fueron las localizaciones más comunes.

El aumento sesgado en la presentación de las formas pulmonares está en relación con la necesidad de derivación quirúrgica especializada por tratarse de un hospital de alta complejidad de las formas atípicas o complicadas que requieren de otros diagnósticos diferenciales y manejo multidisciplinario.

El diagnóstico se basa en los antecedentes epidemiológicos, clínica y exámenes complementarios de imágenes, laboratorio, hallazgos quirúrgicos y anatomopatológicos. Dentro de los exámenes complementarios, las imágenes en función a la localización son pilares fundamentales para la orientación diagnóstica.

Para las formas pulmonares, se utilizan, inicialmente, estudios radiológicos convencionales, a diferencia de la localización abdominal, en la que la ecografía es de elección para la clasificación de la OMS. ${ }^{10}$ Otros estudios, como la tomografía axial computada o la resonancia magnética nuclear, son utilizados para la orientación y la categorización quirúrgica específica. (Figuras 2, 3 y 4)

Para el diagnóstico serológico, se utilizan la hemaglutinación indirecta y ELISA, cuya sensibilidad oscila entre el $50 \%$ y el $98 \%$. El Western blot es de elección para la confirmación serológica de los casos dudosos. La localización pulmonar tiene más falsos negativos que la hepática, con una sensibilidad del 50\%-60\% y $85 \%-98 \%$, respectivamente, que aumenta en los múltiples o rotos al 90\%-100\%. Una serología negativa no descarta la hidatidosis. Nuevas metodologías diagnósticas, como el Ag5 ELISA y la reacción en cadena de la polimerasa (polymerase chain reaction; PCR, por sus siglas en inglés), se encuentran en evaluación con el objetivo de mejorar la sensibilidad. ${ }^{11}$ Es por eso por lo que la presencia de una masa quística en un paciente con antecedente de exposición a perros y ovejas en aéreas donde el E. granulosus es endémico validaría el diagnóstico de hidatidosis. Sin embargo, siempre debe realizarse el diagnóstico

Tabla 1. Resultado de las características epidemiológicas, clínicas, diagnóstico, tratamiento y evolución. N: 47 pacientes

\begin{tabular}{lll}
\hline Variables & Número (n) & Porcentaje (\%) \\
\hline Edad al momento del diagnóstico (mediana en años) & 8 (rango: 3-17) & 51 \\
Sexo masculino & 24 & 98 \\
Epidemiología positiva & 46 & 62 \\
Procedencia rural & 29 & \\
Tiempo al momento del diagnóstico (mediana en meses) & 3 (rango: 1-32) & 44 \\
LOCALIZACIÓN: & 54 & 39 \\
$\quad$ Pulmonar & 24 & 11 \\
$\quad$ Hepática & 21 & 2 \\
$\quad$ Cerebral & 6 & 2 \\
$\quad$ Ocular & 1 & 2 \\
$\quad$ Renal & 1 & 85 \\
Comproperitoneal & 40 & 30 \\
Quistes múltiples (en uno o más parénquimas) & 14 & 15 \\
Quistes multiorgánicos & 7 & 23 \\
Eosinofilia (> 500/mm $\left.{ }^{3}\right)$ & 11 & 45 \\
Serología positiva (ELISA) & 21 & $\mathbf{9 6}$ \\
Tratamiento médico-quirúrgico & 45 & 91 \\
$\quad$ Cielo abierto & 41 & 7 \\
$\quad$ Laparoscopía & 3 & 2 \\
PAIR & 1 & $\mathbf{2 8}$ \\
Complicaciones & $\mathbf{1 3}$ & 62 \\
$\quad$ Pulmonar & 8 & 23 \\
Hepática & 3 & 15 \\
Cerebral & 2 & 6 \\
\hline Recaída & 3 & \\
\hline
\end{tabular}

PAIR: punción, aspiración, inyección de escolicida y reaspiración; ELISA: enzimoinmunoanálisis de adsorción. 
diferencial con otras patologías quísticas, como quistes benignos, tuberculosis, micosis, abscesos o tumores. Debe solicitarse la radiografía de tórax a todos los pacientes que tienen hidatidosis hepática para descartar la localización pulmonar, así como el estudio de sus contactos familiares para evaluar la presencia de parasitosis en otros miembros de la familia.

El tratamiento se realiza sobre la base de los consensos nacionales e internacionales de la OMS. ${ }^{2,4}$ La mayoría de las guías se basan en la opinión de expertos, ya que no hay estudios comparativos con alto nivel de evidencia. Hasta 1980, la cirugía era la única opción terapéutica; sin embargo, los antiparasitarios y la aparición de nuevas metodologías percutáneas han ido reemplazando las exéresis convencionales.

\section{FIgURA 2. Localización pulmonar}

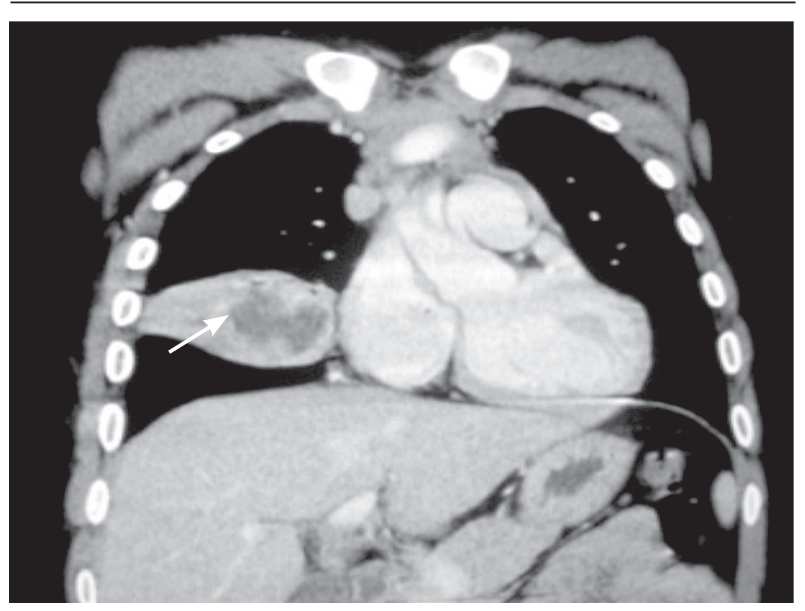

Tomografía axial computada de tórax.
Puede resumirse en 4 modalidades terapéuticas básicas: la cirugía convencional, las técnicas percutáneas, los antiparasitarios y la modalidad de la no intervención. La elección quirúrgica depende de la clínica, la localización, el tamaño, las características del quiste y la experiencia del operador. ${ }^{3}$ En cuanto a las técnicas quirúrgicas recomendadas, más frecuentes son la cirugía a cielo abierto (radical o conservadora) y la cirugía laparoscópica. Dentro de las percutáneas, la punción, aspiración, inyección de escolicida y reaspiración (PAIR). La cirugía convencional es la técnica de elección en pacientes sintomáticos, quistes de gran tamaño, quistes sobreinfectados o en aquellos con determinadas localizaciones, como la cerebral, pulmonar y renal, con una mortalidad que oscila entre $0,5 \%$ y $4 \%$. La técnica percutánea de PAIR es una metodología mínimamente invasiva utilizada para quistes ubicados, sobre todo, en el hígado y en otras localizaciones abdominales no accesibles por técnicas convencionales. Está contraindicada en caso de quistes hepáticos superficiales y para formas inactivas, calcificadas o con comunicación biliar y quistes pulmonares. ${ }^{12} \mathrm{El}$ riesgo de shock anafiláctico pospunción del quiste se estima en $0,047 \%$, sobre la base de 4209 punciones, de las cuales 16 presentaron dicha complicación. ${ }^{13}$

El tratamiento antiparasitario está recomendado en todos los casos como adyuvante de la cirugía, o bien como tratamiento único en aquellos pacientes asintomáticos que presentan quistes de pequeño tamaño, o bien múltiples en los que no puede realizarse el tratamiento quirúrgico con posibilidades de curación. ${ }^{14}$
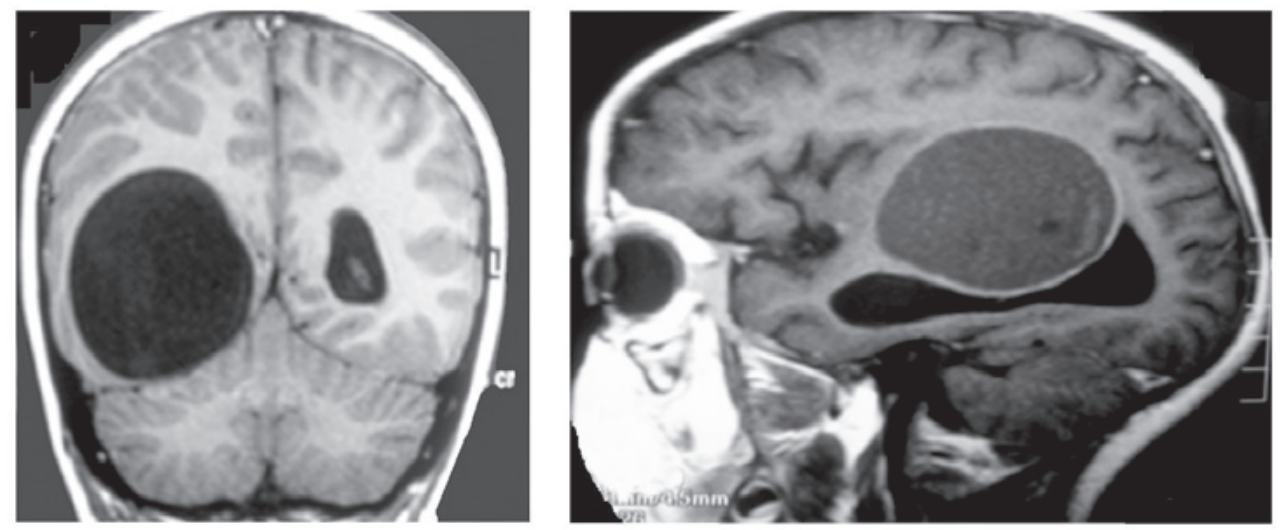

Resonancia magnética nuclear cerebral. 
El albendazol y mebendazol han demostrado ser eficaces en el tratamiento de la hidatidosis; sin embargo, los resultados con albendazol han sido superiores debido a su perfil farmacocinético, absorción intestinal y penetración al quiste. El albendazol es de elección en tratamiento continuo desde el mes prequirúrgico a 3-6 meses posquirúrgicos. El agregado de praziquantel estaría recomendado en accidentes quirúrgicos con rotura de quistes, o bien en las formas graves con el objetivo de prevenir la diseminación secundaria. ${ }^{15}$ La frecuencia y el tipo de complicaciones posquirúrgicas oscilan entre el $8,5 \%$ y el $22 \%$, y dependen, especialmente, de la localización (son más frecuentes en las localizaciones quísticas pulmonares).

En la serie presentada, 13 pacientes (28\%) presentaron alguna complicación; la más frecuente fue en la de localización pulmonar por ser un hospital de derivación. Ninguno falleció a causa de la enfermedad.

Para las estrategias de prevención, modelos matemáticos han mostrado que la intervención más efectiva es la combinación de la vacunación del ganado asociada a la desparasitación periódica canina. Así, se reduce la enfermedad en huéspedes intermediarios y definitivos. Se suma la educación para la salud, que evita la faena domiciliaria y la alimentación de los perros con vísceras de animales.

FIgURA 4. Localización orbitaria

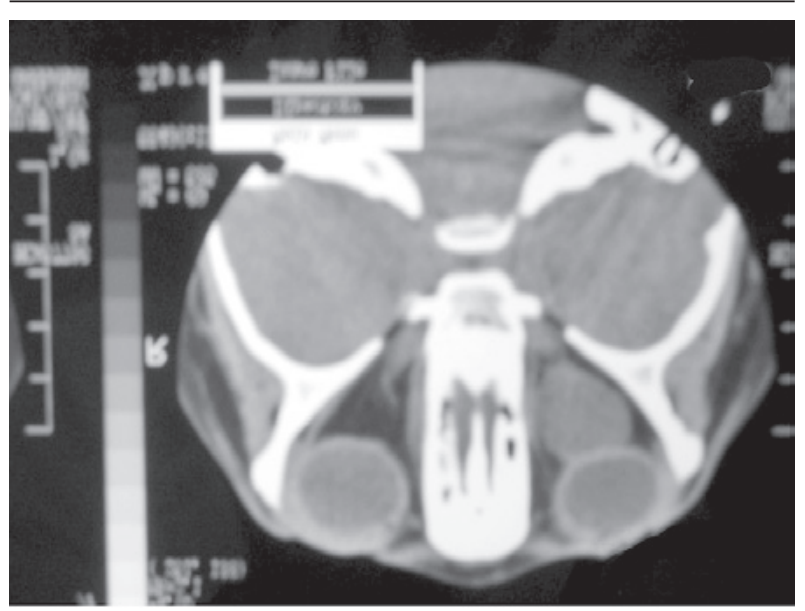

Tomografía axial computada de órbita y macizo facial.

\section{CONCLUSIÓN}

La hidatidosis debe ser un diagnóstico para considerar en niños con lesiones quísticas, en especial, de localización hepática y/o pulmonar, y su manejo requiere de un trabajo multidisciplinario, en el que el enfoque médico quirúrgico resulta prioritario.

\section{REFERENCIAS}

1. Craig P Budka CM, Schantz PM, Li T, et al. Human echinococcosis: a neglected disease? Trop Med Health 2007;35(4):283-92.

2. Enfermedades infecciosas: Hidatidosis. Guías para el equipo de Salud. Buenos Aires: Ministerio de Salud de la República Argentina; 2012. [Acceso: 12 de diciembre de 2016]. Disponible en: http: / / www.msal.gob.ar/images / stories / epidemiologia/pdf/guia-medica-hidatidosis.pdf.

3. Hidatidosis. Casos acumulados hasta la $43^{\text {a }}$ semana epidemiológica. País Argentina por provincia. Años 20152016. Boletín Integrado de Vigilancia 2016;338(SE48):82.

4. BrunettiE, Kern P, Vuitton DA, Writing Panel for the WHOIWGE. Expert consensus for the diagnosis and treatment of cystic and alveolar echinococcosis in humans. Acta Trop 2010;114(1):1-16.

5. Moro P, Schantz P. Echinococcosis: a review. Int J Infect Dis 2009;13(2):125-33.

6. Consenso sobre enfermedades infecciosas regionales en la Argentina. Recomendaciones de la Sociedad Argentina de Pediatría-Comité Nacional de Infectología. 2012-13. [Acceso: 12 de diciembre de 2016]. Disponible en: http: / / sap.org.ar/docs / profesionales / consensos / consenso_ patologia_regional.pdf.

7. Schaefer JW, Khan MY. Echinococcosis (Hydatid Disease): Lessons from experience with 59 patients. Rev Infect Dis 1991;13(2):243-7.

8. Moscatelli G, Abraham Z, Moroni S, Martínez Iriart E, et al. Hidatidosis pulmonar. Arch Argent Pediatr 2012;110(3):265-6.

9. Tapia O, Vidal A, Antonio L. Hidatidosis cerebral: aspectos clínicos eimagenológicos. Reporte de 4 casos. Rev Med Chile 2012;140(3):358-63.

10. World Health Organization. International classification of ultrasound images in cystic echinococcosis for application in clinical and field epidemiological settings. Acta Trop 2003;85(2):253-61.

11. Paganozzi D, Addis MF, Biosa G, Roggio A, et al. Diagnostic Accuracy of Antigen 5-Based ELISAs for Human Cystic Echinococcosis. PLoS Negl Trop Dis 2016;10(3):e0004585.

12. Brunetti E, Junghanss T. Update on cystic Hydatid disease. Curr Opin Infect Dis 2009;22(5):497-502.

13. Smego RA Jr, Bhatti S, Khalij A, Beg MA. Percutaneous aspiration-injection-reaspiration drainage plus albendazole or mebendazole for hepatic cystic echinococcosis: a metaanalysis. Clin Infect Dis 2003;37(8):1073-83.

14. Junghanss T, da Silva A, Horton J, Chiodini PL, et al. Clinical management of cysic echinococcosis: state of the art, problems, and perspectives. Am J Trop Med Hyg 2008;79(3):301-11.

15. Arif SH, Shams-Ul-Bari, Wani NA, Zargar SA, et al. Albendazole as an adjuvant to the standard surgical management of hydatid cyst liver. Int J Surg 2008;6(6):448-51. 